Robert Hassan, 'Network Time and the New Knowledge Epoch', Time and Society, vol. 12, no. 2/3 (2003), pp. 225 241.

This in an electronic, pre-publication version of an article published in Time and Society. (C) Copyright Sage Publications. Reproduced with permission. For further information see < http://tas.sagepub.com/>.

\title{
Network Time and the New Knowledge Epoch
}

\section{Robert Hassan}

\section{Introduction}

The relationship between temporality and the production and dissemination of knowledge is something that has been given relatively little attention in social and cultural theory. A tendency has been to touch upon this connection in an implied or tangential fashion. A common approach is to make the link through technology, or technological innovation. This would seek to show that a quantum technological development such as the printing press, for example, has 'speeded up' the production and dissemination process; or more recently that computers and computerization have had the same effect - only to a much greater degree in terms of the time factor (massively shortened) and the quantity of knowledge being produced (enormously expanded) (Rifkin, 1987, 1995; Castells, 1996; Shenk, 1997). There is not a great deal concerning the connections themselves what these might be, how they may function, what their effects may entail, and so on. Moreover, such perspectives tend to be refracted through the fairly static metaphysical categories of what constitutes time and knowledge that stem from the works of, say, Kant, Husserl, Bergson or Heidegger.

More recently, social theorists with an interest in the relationship between time and the sociology of knowledge have looked at this connection in a more nuanced and real-world way. These, too, though, have tended to be partial treatments in the context of a more generalized focus. Barbara Adam, for example, argues that there exist a 'multitude of times' - for example in consciousness, memory, narrative and physiology - 'which interpenetrate and permeate our daily lives' (1995: 12). These temporalities, however, have suffered displacement or sublimation due to the overpowering domination of clock-time, a process that began in a systematic way during the industrial revolution. Nevertheless, this complex of temporalities still make themselves felt as part of our everyday lives, Adam maintains, and produce their own 'contextually situated' knowledges through the localized refractions of culture, history, language, place and space (p.161).

Helga Nowotny (1994), in a book that deals with the connections between time, modernity and postmodernity, makes the important observation that 'new knowledge arises under changed conditions of creation and in changed structures of organization' (p. 87). In particular, among the new 'structures of organization' that heralded the new age of modernity was the growth in scientific knowledge that accompanied the industrial revolution, and this came replete with its own 'dynamized' time based upon the 
clock (pp. 87-8). Postmodernity brought its own 'structures of organization' that created their own 'new' know- ledges. An important effect of this process, Nowotny argues, is that new technicized 'structures of organization' caused 'vast destruction' of 'old' knowledges (p. 88).

In this article I want to build upon the insights offered by these two theorists to look more closely at the connections between temporality and knowledge production. The analysis will take a broad historical perspective that looks at the connections between knowledge and temporality during the industrial revolution, and contrast these by looking at the connections in the contemporary era between neoliberal globalization and the information and communication technology (ICT) revolution. Several questions will be explored. For example, how do humans acquire and produce knowledge? What are the temporal dimensions of the process? What effects did the growing domination of clock-time since the early 19th century have upon the forms of knowledge that were produced in industrializing societies? And, moving the analysis to our own time: how have the ICT revolution and the growing insertion of what I have termed 'network time' into our 'structures of organization' affected the forms of thinking and knowledge production that have been shaped and dominated by clock-time?

\section{Temporality and Knowledge Production}

My starting point, following from Adam, Nowotny and others, is that temporality and knowledge are not singular, universal 'things', but instead are processes, techniques, understandings and experiences that are marked by diversity and multiplicity that suffuse and help shape our being-in-the-world. We can readily relate to this if we think about it. I can do something, a task, say, in 'my own' time, when it 'feels right', or when I 'want to'; or I may do so under a shared temporal regime, in accordance with others, organized by the clock, or the calendar, or the seasons, or when the sun goes down. Similarly with knowledge, or knowing, there are things that only I 'know' about (or believe I do); there are also many other forms of knowledge that are public and widely shared; and some again that are privileged or specialized and accessible only to a select few. Irregular experiences of temporality and diverse ways of knowing have been integral to being human in the world. For tens of thousands of years, pre- industrial humanity lived in and through a perpetual flux of differing temporalities and different ways of knowing and of producing knowledge. This was a profoundly dialectical process, whereby people and groups interacted with their environments. Differing environments and differing cultures produced differing relationships to time and differing conceptions of time; and the knowledges produced were themselves unique to the circumstances of their emergence.

Much of this is familiar, but what of the mechanics of the process? For example, how do humans produce and acquire knowledge, and what are the temporal dimensions of this process? To simplify to the extreme, the sensual world around us comes to us as data. The word 'data' comes from the Latin meaning 'things given' and in this context refers to the signals and symbols that confront us in raw form in the world around us as they act upon our senses, primarily our eyes and ears. In this raw, 'given' form it is simply a vast mass of data with no intrinsic meaning. To the 'untrained' eye and ear the world would seem chaos of shape, colour and sound. We first have to attribute meaning to this raw data.

Robert Hughes, in his 1986 book The Fatal Shore, has described how this works in practice. He tells the story of the British ships that arrived in Australia in 1770 at a place they called Cape Everard. The Aboriginal fishermen in the bay 'saw' the ships approaching them, but went on fishing, seemingly oblivious to their presence. The height and shape of these ships were so fantastically alien to these indigenous peoples' 
frames of reference that they simply ignored them. They possessed no adequate way of response. In other words they could see the ships, obviously, but they held absolutely no meaning. However, if they had seen these ships, or similar ships before, then these shapes would have had some meaning, some frame of reference, in which case the raw data that comprised the ship or ships could have been processed into information. The root of this word again is Latin, informare, and means 'to describe'. Information is then a description, a statement of data in the abstract that contains meaning. From this it may be argued that the imputation of meaning into raw data stems from experience. Experience is the lived processes that constitute the participation in events and activities, engendering both recognition and a contextual frame of reference through which to process data. These are processes deeply grounded in temporality, and, to borrow a phrase from Hörning et al., result in 'temporalized experience' (1999: 302). Differing temporalities help govern and shape differing experiences. Experience is duration and vice versa, and this provides the last link in the chain of transformations from raw data into knowledge. Knowledge builds, like sedimentation, over time. It develops, is validated and legitimated through a heuristic framework of what Kant called 'prior knowledge'. This is the sum of experience, individual and collective, historical and contemporary, working upon emerging data and information, and is the prism through which new knowledge is refracted and formed.

Temporality, then, provides content and form to the kinds of knowledge that are produced. And for thousands of years the 'multitude' of temporalities that exist produced their own, infinitely variable 'contextually situated' knowledge that developed in response to their own specific conditions of emergence. Prior to the rise of the industrial revolution, all societies, be they tribes, bands, empires or civilizations, were always already 'knowledge societies'. These produced forms of everyday and specialized knowledges, some that are still with us, some that are irretrievably lost, that corresponded to each society's 'structures of organization' and the temporalities that suffused them. The arrival of the industrial revolution changed this world of perpetual flux of temporalities and knowledges forever, and humanity embarked upon what we can see in retrospect was the first knowledge epoch.

\section{Clock-Time and the First Knowledge Epoch}

The choice of the noun 'epoch' to denote this temporal duration is deliberate. It indicates a historical existence of a time-phase of particularity. This epoch emerged through the historical convergence of four principal dynamics, beginning around the mid-18th century. These are: capitalism and commodity production; the revolutions in science and technology; the influence of the Enlightenment; and the widespread suffusion of clock-time in industrializing cultures and societies. Knowledge production emanating from these converged and 'dynamized' processes began to take on particular epoch-making forms. Fundamentally, much new knowledge production and dissemination began to be oriented towards the needs of capitalism and capitalist industry. The intrinsic role of clock-time in the development of a 'capitalist time consciousness' is well known (Thompson, 1967; Thrift, 1981; Adam, 1995). The important point to make about this is that clock-time consciousness and clock-time logic also shaped and metered much of the new knowledge that was being produced and disseminated - clock-time based knowledge, we might call it. In other words, if machines, processes, organizations, forms of production and distribution have the meter of the clock built into them, and are 'time-loaded' through our 'time practices' as Hörning et al. have argued, then so too do the forms of knowledge that made them possible (1999: 294). ${ }^{1}$ 
Here I refer to a particular kind of knowledge that emerges 'entimed'(Hörning et al., 1999: 279) with clocktime logic - instrumental knowledge, stemming from instrumental reason. Instrumentalism is what gets things done, and is the dynamo that made capitalist materialism so world-conquering. Instrumentalism takes the world largely as given and attempts to find means of living ever more productively and efficiently in it. Working within a narrow horizon of epistemological assumptions, knowledge is valued here insofar as it has a use value (Barnett, 1997: 91). As knowledge is valorized under instrumental logic, then so too is time, making speed (doing things faster, more efficiently, within the bounds of clock-time) an essential element in its production processes.

However, the influence of the Enlightenment also brought another tradition of reason, critical reason. Critical reason is the dialectical antithesis of instrumental reason. Unlike instrumental logic, it has not been suffused by 'capitalist time consciousness'; it works upon different epistemological assumptions that render it unsuited to singular, linear and universal 'entimement' by the clock. Since the industrial revolution, critical thinking, producing critical forms of knowledge, has acted as a check upon what would be the undoubtedly baleful effects of pure instrumentalism. Nevertheless, since the industrial revolution the dialectic has operated in some sort of balance, producing other forms of knowledge, other disciplines and sciences, not necessarily commercial, but based upon Enlightenment principles of knowledge for the sake of knowledge. This form of thinking has provided the intellectual facility to counter purely goal and action-centred forms by subjecting them to the test of critical and reflexive evaluation. Such critique would not be constrained by the 'immediate' and the epistemological assumptions that may stem from the instrumental worldview. Rather, it would draw upon other knowledges, based, possibly, upon other temporalities; these may be marginal or new, or old, or alternative, and would add the critical, reflexive dimension to the problems and challenges, individually and collectively, that people and societies may face.

In an ideal world, symmetry between the two is required and, indeed, the inter-actions between instrumental and critical forms of knowledge are sometimes, as C. Wright Mills (1970: 350) put it, 'in effective touch'. These moments of 'effective touch' are the optimal moments 'of the creation of imaginary alternatives' -the times when humanity does its best work (Barnett, 1997: 6). It is these instances that have pushed the frontiers of western thinking forward towards the many benefits that have been bestowed upon culture and society. Taking a broad perspective, it becomes clear that the trajectory of capitalist development, powered by the dynamics of the revolutions in science and technology, the traditions of Enlightenment thinking, and the deep and widespread suffusion of clock-time, has been one of tremendous growth in both instrumental and critical forms of knowledge. However, with the growth in instrumental and critical knowledge production came the increasing domination of the latter over the former. The logic of capitalism, expressed as economic, social and class power, is armed with the a priori 'truths' of the instrumentalized view of the world. And as capitalism became more complex, more powerful and all encompassing, its instrumental logic has gradually came to displace, marginalize and extinguish the production of critical knowledges and the spaces of dissent and difference that helped to produce them (Agger, 1992).

Domination by instrumental reason (though in ways that have not examined the role of clock-time upon the production of knowledge) has been a familiar theme since at least the 1940s when the Frankfurt School began to develop its critiques. However the question is not one of a simple determinism, either by technology, or clock-time, or instrumental rationality or by the commodifying logic of capitalism itself. It is a question of the combined action of all of these forces. Since the beginning of the 20th century, when the capitalist mode of production increasingly began to be seen as the 'natural' mode of human organization, the 
creation (even in theory) of 'imaginary alternatives' and critical forms of thinking have dwindled in relative terms. Since the fall of communism, especially, 'alternatives' that would posit new ways of organizing social life, ways not mandatorily underpinned by the 'free market', and competition and commodification, have gradually and inexorably been consigned to the margins of what is considered useful and legitimate as knowledge. Communism's final demise was assisted by another revolution, one that began in the West around the late 1970s. This was the revolution stemming from the interactions of neoliberal globalization and the communications technology revolution. This revolution helped to spread the 'entimed' logic of capitalism still further - into almost every nook and cranny of culture and society, into areas which, according to Frederic Jameson, had been 'hitherto sheltered from it and indeed for the most part hostile to and inconsistent with its logic' (1996: 9).

Adam's 'contextually situated' temporalities, spaces of difference and diversity, and sites of resistance still exist. Indeed as Raymond Williams argued, social-economic processes such as commodification, domination and standardization can never exhaust all human experience, and spaces will always exist where difference and subversion can be created (1979: 252). However, these are increasingly pressurized and marginalized by new, volatile and powerful 'structures of organization' based on market globalization and information technologies. These dynamics have brought us to the threshold of a new knowledge epoch. Its developmental trajectory remains as yet unclear, but it brings with it anew temporality - one that is set to change the mechanics of knowledge production once more - and that is real-time.

\section{Real-Time and the New Knowledge Epoch}

Around the 4th century AD, Saint Augustine, Bishop of Hippo (now Annaba, Algeria) was credited with coining the following (by now well-worn) aphorism: 'What, then, is time? If no one ask of me, I know; if I wish to explain to him who asks I know not.' Over the centuries, time has not become any easier to understand. With the advent of the ICT revolution, globalization and the network society, 'real-time' has emerged as the latest techno-social temporal form to challenge our intellectual and cognitive powers. How do we think and talk about real-time? Is it a radically new form of time, one that disrupts and disturbs the comfort zone of clock-time that we had finally become used to after two centuries of its suffusion into our everyday lives? Or is it simply a marketing concept, a term bereft of content, a slogan to make us believe that this or that product or application must be super-efficient because it operates on the exciting-sounding plane of 'real-time'?

A literature search will quickly reveal that much that has been written about real-time comes from a technical perspective. This is unsurprising. Real-time is used mainly by computer programmers and systems designers to describe operating systems that respond at high speed to the input of data. The computer technicians' online dictionary of Internet terms defines real-time as something 'occurring immediately'; and on a surface level at least, this is how most people would conceive of real-time. However, this generalized definition, stemming as it does from a technical perspective, sheds little light on the social and cultural implications that 'occurring immediately' may signify. Michael Heim, in his The Metaphysics of Virtual Reality, gives a more intriguing definition. He writes that real-time is 'Simultaneity in the occurrence and the registering of an event, sometimes called synchronous processing' (1993: 157). This represents a significant shift from the technical definition. 'Immediately' connotes a brief temporal lag (be it measured in minutes, seconds, or even nanoseconds), whereas 'simultaneity' suggests 'happening at the same time', a cancelling- 
out of temporal duration between events. Simultaneity implies, then, a non-time, or as we shall see shortly, the shattering or death of time.

This concept of real-time 'simultaneity' is one that has entered the discourses of the social sciences and the humanities through literature - or more precisely through its sci-fi sub-genre, cyberpunk. As Paul A. Taylor has argued, neologisms contained in the novels of William Gibson such as Neuromancer (1984) or Neal Stephenson's Snow Crash (1992) provide 'zeitgeist-capturing qualities' that 'provide fresh insights into the cultural experience of a society increasingly transformed, not only by the extent of technological change in a new informational age, but also its unprecedented pace' (Taylor, 2001: 74). Gibson's work has been especially fecund in this regard. His concept of the 'matrix', a dataspheric 'non-space' (1984: 81) is a term that resonates closely with our concept of the Internet. Gibson's 'matrix' is a destroyer of space and time, a virtual space that operates in real-time. As Heim makes clear in his fairly long exegesis on Gibson's work, the 'matrix' is 'simultaneity'.

There exists the danger, however, that the use of conceptual categories emerging from sub-genres of literature as a way to articulate the new technotemporal 'zeitgeist' can skew our perspective if we take the term too literally. Concepts taken literally, or in ways half-understood, or ideologically misrepresented, have a way of attaching themselves to academic discourses and evolve through time and more discourse into accepted truths. Adam Smith's 'hidden hand' of market forces is one example of ideological manipulation; and 'realtime' is another term that has been taken literally, with no real thought as to what it may imply. Heim falls into this trap in his attempt to articulate a metaphysics of real-time. In sociology, Manuel Castells, in his influential 1996 book The Information Age: The Rise of the Network Society argues that globalization and the information age are heralding the era of domination by real-time, or what he calls 'timeless time'. Real-time for Castells is also a kind of 'non-time', which means that as the network society becomes more encompassing of culture and society, 'linear, measurable, predictable time is being shattered ... in a movement of extraordinary historical significance' (1996: 433). In his speculative social theory, Paul Virilio is even more explicit when he writes that "the teletechnologies of real-time . . are killing "present" time by isolating it from its here and now, in favour of a commutative elsewhere that no longer has anything to do with our "concrete presence" in the world'(1997: 10).

Such examples, I think, are indicative of the tendency to adopt concepts that have migrated from literature, apply them literally, and then take them to an extreme when trying to articulate reality. Through their ability to 'shatter' or 'kill' time, Castells and Virilio imply that ICT-generated real-time is about to envelop culture, economy and society in a 'timeless time', a non-time where everything happens simultaneously. Of course, if we posit it in this way, as these authors compel us to, then the idea becomes absurd. Such a world would be Gibson's 'matrix', existing in Heim's 'simultaneity' where we humans exist as binary code within its realtime domain. In our actual day-to-day existence our intuition as well as our experience would lead us to reject such a notion as 'timeless time'. The act of being in the cultural, social world constitutes time, and the experience of temporality is (potentially) too varied, too disconnected and too interpenetrative to be 'killed' by a technology. We breathe in time, we dream in it, we imagine in it, we remember in it, we anticipate it and we approach death in it. Time is fundamentally embodied in everything we do. Moreover, thinking in a commonsense fashion about ICTs such as the Internet, and our interaction with them, the concept of 'timeless time', or the death of time, do not come close to our actual experience. 'Jacking into the matrix' via a data port on the back of your neck, and exploring the data sphere as binary information, as Gibson's 
protagonists do, is not on a par, one can readily appreciate, with the rather more prosaic activity of surfing the Internet.

But, for the sake of argument, let us say that Castells and Virilio (and many others who have picked up on this) simply mean clock-time when they predict imminent temporal demise. Clock-time, as we have seen, is a social construction and therefore able, in theory at least, to be de-constructed, killed off or rendered 'timeless'. Or is it? Environmental philosopher Arran Gare has noted that: 'The permeation and domination of life by abstract [clock] time has become so complete that it is difficult to realize just how extraordinary this is' (1996: 104). This 'extraordinary' suffusion of the linear meter of the clock means that it is fundamentally embedded in culture and society, and it would be almost impossible to disentangle it from the complexities of everyday life. What Heim, Castells, Virilio and a host of others who herald the birth of the 'virtual society' do not seem to consider is the deep intractability of clock-time. Accordingly, I believe that the term 'real-time' is in fact a misnomer, an inaccurate term to describe the relationship between the ICT revolution and our relationship with a new form of temporality. The term in fact should be done away with in the humanities and social sciences in favour of a much more accurate term with which to describe the new form of temporality that is beginning to suffuse the economy, culture and society - and that is network time.

\section{Network Time}

If we consider the 'entimed' temporality of ICTs in this way, then I think a more accurate description of realworld processes emerges. Network time is digitally compressed clock-time, and as such operates on a spectrum of technologically possible levels of compression. This spectrum is open ended. At one end this may last from a few minutes or seconds, when waiting for a download or for chatroom text to reach the recipient, to, at the other end of the scale, nano- orpicosecond transmissions, which are one billionth and one trillionth of a second, respectively. Time duration is limited only by technical capacities. However, the network is always, in some respect, asynchronous. Networks can fail for a time; they can experience heavy traffic loads that slow them down; emails can be received and read later, as can SMS and voicemail, and so on. The key issue is the network itself, and the general effect of the network is a generalized acceleration.

Interconnectivity is what gives network time its power within culture and society. It stems not simply from the Internet, but from a whole raft of connectable applications and devices that can and will use the Internet as the 'backbone' for interconnectivity. The suffusion into daily life of networkable devices is already impressive if compared with only a decade ago. In many ways the nexus between neoliberal globalization and the ICT revolution represents a triumph of instrumental reason (albeit probably provisionally), so comprehensively is its logic inserting itself into everyday life. Information technologies are central to this process. As Mark Weiser and John Seely Brown (1997: 5) put it, ICTs are 'carrying us through an era of widespread distributed computing towards the relationship of ubiquitous computing, characterized by deeply embedding computation in the world'. The 'embedding' of ICTs in the world is also embedding network time into our everyday lives, at work, at home and in leisure. Almost every new ICT application or device is connectable to the Internet, and the logic of the ICT revolution compels them to be. Globalizing capitalism and the ubiquitous computing that it depends upon mean that networks of interconnectivity are set to deepen and widen, spreading its temporality across more and more realms of life. Email, mobile telephony, SMS text messaging, interactive digital television, Personal Digital Assistants (PDAs), pagers, mobile computing, Bluetooth and WAP-enabled applications, and the Internet itself, are building into an ever-growing thicket of interconnectivity that constitutes the technological framework for network time. 
This dynamic, like the dynamics that suffused clock-time so deeply into the social world and human in consciousness, is being driven by the logic of capitalism. Notwithstanding his rhetorical style, Virilio is instructive here $(1986,1995,1997)$. He has made his life's work the study of the links between speed, technology, and power. His overall thesis can be read as arguing that the logic propelling modernity is a series of innovations in time compression -making things (commodities) faster in time and moving things (people, machines, weapons) faster over space. Capitalism and speed are indissolubly connected, a link described ably by Ben Agger in his Fast Capitalism (1989). And in an economic system where 'time is money', to be able to produce more quickly is to produce more - and more cheaply. The 'revolution' in information technologies has been to take this to another level of temporality, to compress the meter of the clock and to accelerate the time standard of modernity. The creation of the network has simultaneously created a digital environment, an information ecology that generates its own temporality (Hassan, 2000).

Network time does not 'kill' or render 'timeless' other temporalities, clocktime or otherwise. The embedded nature of the 'multiplicity' of temporalities that pervade culture and society and the deeply intractable relationship we have with the clock make this unlikely. Rather, the process is one of 'displacement'. Network time constitutes a new and powerful temporality that is beginning to displace, neutralize, sublimate and otherwise upset other temporal relationships in our work, home and leisure environments. Interconnectivity and networking (the underpinning of neoliberal globalization) is what drives the ICT revolution today. The speed and comprehensiveness of the temporal displacement maybe come somewhat clearer if it is compared with the spread of clock-time through the dynamic processes of the industrial revolution. The spread of capitalism through the industrial revolution was rapid if compared with the spread of earlier modes of production, such as feudalism; and, as we have seen, the meter of the clock was central to this process. However, the suffusion of the clock into culture and society and its installation as the rhythm and meter of life and work were slower and more gradual. This took place following the initial introduction of capitalism. The more systematic capitalism became, the more pervasive the discipline of the clock - the point being that there was always a lag (Thrift, 1996: 193-206). On the other hand, ICTs have what has been termed 'enabling' qualities, meaning that they can be applied across almost all industries, transforming them, and making them ICT-dependent in a very short time. The steam engine or the telegraph, for example, took decades before their influences rippled out to society more generally. The ICT revolution, by contrast, has been widespread and swift. Its logic is prolific and demands that interconnectivity drives the need for more interconnectivity, across more and more industries, bringing more and more people into the information ecology.

Importantly, network time displaces and demobilizes world standard time: the internationalization of clocktime that began when the International Meridian Conference met in the USA in 1884 to standardize time across the world into zones of local time. This local time, although still officially the geo-temporal meter which most of us still recognize, set our watches by and organize the train schedules upon, is being shunted towards the sidings by the time(s) of the network. We may still wear our watches, but I suspect we are looking at them less. The meter of our day is more likely to be synchronized to the network and its internal $a$ synchronicity. Increasingly, then, the growing number of ICT devices and applications that comprise the network ecology begins to shape our relationship to a new, emptied and de-temporalized successor to the clock - the network. 
The asynchronous times of the network may at first glance offer something better than the rigid meter of the clock: furnishing a potential for diversity, for the creation of innumerable original 'contextually situated' spaces where difference can flourish, and where new ideas and new knowledges may be produced. However, as I argued previously, the network has its own meta-logic, one that stems from the imperatives of capitalist accumulation, production and consumption. It reflects the social and economic forces that build it and is essentially market-oriented and instrumental. And as it connects, so too does the network society tend to isolate and alienate. As Jeremy Rifkin (2000: 55) argues, digital networks:

... relentlessly constitute and reconstitute us as 'focus groups', 'niche markets', 'demographics', 'zones',
'customer profiles' and so on, to be classified, bought and sold just like any other commodity. In the real
time information economy we become database-constructed identities that are continually broken down and
reformed in tandem with market-competition imperatives.

Indeed, seen in this perspective, network time is even more dictatorial than the clock, because unlike the clock, the network is unpredictable, volatile and chaotic; but it has an inner logic (that of commerce and instrumentality) that we adapt ourselves to and have difficulty in exercising control over. Moreover, the 'shared experiences' through the 'shared temporality' of the clock, however manipulative and exploitative these may have been, did contain the spaces and the 'time' for reflection, organization and resistance in ways the network leaves no time and no space for.

The blurring of the lines between work, social life, family life and personal life resulting from the globalization/ICT nexus has been well documented. The network society and its interconnected human dimension have created the '24-hour economy' and the on-call '24-hour worker'; only like 'real-time', '24hour' is also a misnomer, and may more accurately be described as the 'network economy and the network worker'. The socio-cultural temporal rhythms that evolved over the last 200 years, such as weekends, nineto-five workdays, family time, prescribed holiday times, and so on are becoming a thing of the past as the need for extreme flexibility carries the economy and the temporality of the network into almost every aspect of our lives. Temporal displacement now occurs every time we connect to the network. Network time interrupts our routine time in the form of a new temporal experience. Indeed, the ability to be connected, to live and work in network time is being argued as a social right in many developed economies: a socialdemocratic project that merely drives more people to spend more of their time in the network simply to improve their life-chances. As Castells (1998) argues:

Be in the network, and you can share and, over time, increase your chances. Be out of the network, or become switched off, and your chances vanish since everything that counts is organised around a world wide web of interacting networks.

The more we become connected and dependent upon interconnectivity in our jobs and in other aspects of our lives, the more we will live in an accelerated mode. From at least the time of Marx and Weber there have been theorists who have argued that life is continually 'speeding up'. However, the locus of this acceleration has tended to be attributed rather vaguely to new technologies, to 'modernity', to 'technical rationality', to 'capitalism' and so on. However, since the time of Marx and Weber the clock has been our unchanging meter and scheduler, and so it was not always clear what the exact locus of 'acceleration' was. I argue that in the ever-increasing realm of interconnectivity within the network society we have an empirical/technical instance of the 'acceleration' actually taking place through digital compression of clock-time. 
The question now is: if it is accepted that temporality and knowledge production are intricately linked in the ways I have argued they are, what effect does the growing realm of the network have upon the production and dissemination of knowledge?

\section{Knowledge Production in Network Time}

To paraphrase Helga Nowotny: the information technology revolution has brought its own dynamized structures of organization. These digital structures permeate the economy, culture and society to a degree that is historically unsurpassed, creating in the process a distinct 'information ecology'. This ecology creates and sustains its own temporality, the chronoscopic time of the network, and this chrono-digital ecology helps to shape and form the kinds of new knowledges that are now being produced. In short, the knowledge being produced in this new knowledge epoch reflects the needs and imperatives of the neoliberal knowledge society. And to extend Nowotny once more, these new structures of organization tend to destroy or marginalize 'old' forms of knowledge, forms no longer suited to the tempo and instrumentalism of the chrono-digital ecology.

In this accelerated ecology, the creation and application of reflexive knowledge and reflexive evaluation becomes increasingly difficult. There is simply less time for it - and less perceived need for it in an increasingly competitive and profit-driven social-economic system. A major consequence is that we are intellectually ill equipped to understand what Adam (2003: 78) terms the present-day 'human-technologyscience-economy-equity-environment constellation'. In other words we understand our world less because it is a world that is increasingly out of our control. Adam continues that in such an environment it is impossible to fully appreciate:

... that people are the weakest link when the timeframes of action are compressed to zero and effects span to eternity, when transmission and transplantation are instantaneous but their outcomes extend into an open future, when instantaneity and eternity are combined in a discordant fusion of all times.

When people are 'the weakest link' in this chrono-digital ecology of our own making, then one of the central ironies of the information age becomes apparent. In the name of 'efficiency', neoliberalism has abrogated social control to both 'market forces' and computer networks of automation. Even those 'in control', those in the boardrooms and cabinet offices of the great and powerful are essentially 'out of control' as their 'timeframes for action' are set in the present or the near future, with the consequences of their actions, as Adam reminds us, spiralling out into an unknown eternity. We have less time to think about the future, because a 'competitive market environment' compels us to think 'fast' and apply instrumentalized knowledge to the here and now.

We can see the shift in the mechanics of knowledge production in the recent metamorphosis of the university, an institution which Delanty terms 'a key institution of modernity . . . the site where knowledge, culture and society interconnect' (2001: vii). In the major industrial countries since the 1980s, the universities have become a 'massified' tertiary education sector that has been oriented substantially toward the perceived skills needs of the economy. They have become, as Marginson and Considine (2000) have argued 'enterprise universities' that operate on an increasingly commercial basis in a commercial environment. They are also some of the most densely informationalized spaces in society, and, along with 
the media industries that they help train and staff after graduation, act as significant knowledge 'nodes' in the globalized network (Hassan, 2003).

The 'liberal education' that once was the central raison d'etre of the university is viewed increasingly as a time-consuming irrelevance. More and more students see the university as an unremarkable 'skill centre' that will furnish them with the knowledge (the 'facts' and technical skills) to maximize their potential in the job market (Schiller, 1999: 144; McInnis, 2001). Those disciplines in the social sciences and humanities that are economically disinterested, such as philosophy, politics, history, social theory and so on, continue to languish and be marginalized by the real business of the enterprise university which is accountancy, computer sciences, programming, marketing, hospitality and tourism, and so on.

Moreover, the network society and the universities that are such an important knowledge-producing part of them produce vast amounts of information, the 'raw material' of knowledge. A study at the University of California at Berkeley estimated in 2002 that over the next three years alone, more information would

be created than was made over the last 40,000 years (Cochrane, 2002). This constitutes what Shenk (1997) calls the 'data smog' of the network society, the major public health problem for the digital age. Further, Shenk argues that this information overload has consequences for how we think and how we make sense of the world. He quotes Michael Dertrouzos, director of MIT's Laboratory for Computer Science, as saying that information overload 'occupies the brain and reduces productivity' (1997: 30). Again, no small irony, if it were true, in a neoliberalized culture and society that prides itself upon its superefficiency through the use of ICTs. However, I do not believe that our minds have become clogged with an overload of information. We instead teeter on the brink of it all the time. We 'adapt' to our new chrono-ecology through thinking 'smart', by judging (based upon criteria shaped by the neoliberalized network society itself) what we really need to know in our own lives. In other words, we develop what I have termed a form of 'abbreviated thinking' to help cope with the potential overload and make life seem in some way manageable. And, of course, the network is ideally suited for such thinking. We skim, we surf, we browse and we chat.

We are at the beginning of a new knowledge epoch, where knowledge is produced and disseminated in and through a newly constructed environment, through what Nowotny terms 'changed conditions of creation' (1994: 87); a digital environment that has its own temporality - that of the network. We are also at the beginning of the process of the changing nature of socially constructed knowledge, where instrumental knowledge dominates in an unprecedented way. At this early point the trajectory of the process is unclear, but it is possible to locate the problems and establish where to look for solutions. The problem is the nexus between neoliberal globalization and the ICT revolution; and the solutions are political.

To break the nexus between neoliberal globalization and the ICT revolution would be to begin to control the spread and the comprehensiveness of network time in people's lives. It would allow ICTs to work in the service of humanity as opposed to the narrow interests of business. Breaking the nexus will require a sea change, a political revolution that would make the market and information technologies work for cultures and societies instead of the other way round. Until this happens network time will spread and compel more and more of us to try to synchronize with what Adam (2003) calls the networks' 'discordant fusion of all times'. We will rapidly become accustomed to living in a constant present and our understanding of who we are will emerge through the context of the knowledges that are produced within it. Ultimately, capitalism (or this current version of it) will be thought of as the only possible mode of organizing economic life (has it not 
already?), and critical thinking, other ways of being and seeing and other temporalities of experience will become, literally, unthinkable.

\section{Notes}

1. Hörning et al. are in fact ambivalent on this point. They argue that there is a dialectical relationship whereby temporal practices embedded in everyday life are indeed reflected in the technologies society produces, but that 'entimed' technologies 'constrain as well as enable', provoking 'new time practices' that feed into the development of newly 'entimed' technologies. I also argue that there is a dialectic in operation, and this is reflected in the interactions between 'instrumental' and 'critical' thinking and the knowledge production and technological development that has emerged since at least the beginning of the Enlightenment. I argue later in this essay that instrumental forms of thinking in this dialectic have gradually supplanted critical thinking. This process reaches its high point with the nexus between neoliberal globalization and the ICT revolution - a high point that inaugurated a new knowledge epoch.

\section{References}

Adam, Barbara (1995) Timewatch. Cambridge: Polity Press.

Adam, Barbara (2003, in press) Time. Cambridge: Polity Press.

Agger, Ben (1989) Fast Capitalism. Urbana: University of Illinois Press.

Agger, Ben (1992) The Discourse of Domination. Evanston, IL: Northwestern University Press.

Barnett, Ronald (1997) Higher Education: A Critical Business. Buckingham: Open University Press.

Castells, Manuel (1996) The Information Age: The Rise of the Network Society. Oxford: Blackwell.

Castells, Manuel (1998) 'Information Technology, Globalization and Social Development'

http://www.unrisd.org/infotech/conferen/castelp1.htm

Cochrane, Nathan (2002) 'Managing the Store', The Age (Australia), 5 November.

Delanty, Gerard (2001) Challenging Knowledge: The University in the Knowledge Society. Buckingham:

Open University Press.

Gare, Arran (1996) Nihilism Inc. Sydney: Eco-Logical Press.

Gibson, William (1984) Neuromancer. London: Gollancz.

Hassan, Robert (2000) 'The Space Economy of Convergence', Convergence 6(4): 18-36.

Hassan, Robert (2003, in press) The Chronoscopic Society: Globalization, Time and Knowledge in the

Network Economy. New York: Lang.

Heim, Michael (1993) The Metaphysics of Virtual Reality. New York: Oxford University Press.

Hörning, Karl H., Ahrens, Daniela and Gerhard, Anette (1999) 'Do Technologies Have Time?', Time \& Society 8(2): 293-308.

Hughes, Robert (1986) The Fatal Shore. New York: Knopf.

Jameson, Fredric (1996) 'Five Theses on Actually Existing Marxism', Monthly Review 47(11, April): 9.

Marginson, Simon and Considine, Mark (2000) The Enterprise University: Power, Governance and

Reinvention in Australia. Cambridge: Cambridge University Press.

McInnis, Craig (2001) 'Signs of Disengagement: The Changing Undergraduate Experience in Australian Universities', Inaugural Professorial Lecture,

http://www.cshe.unimelb.edu.au/downloads/InauguralLecture.pdf

Mills, Charles Wright (1970) The Power Elite. New York: Galaxy Books. 
Nowotny, Helga (1994) Time. Cambridge: Polity Press.

Rifkin, Jeremy (1987) Time Wars. New York: Henry Holt.

Rifkin, Jeremy (1995) The End of Work. New York: Putnam.

Rifkin, Jeremy (2000) The Age of Access. London: Penguin Books.

Schiller, Dan (1999) Digital Capitalism. Cambridge, MA: MIT Press.

Shenk, David (1997) Data Smog. New York: Abacus.

Stephenson, Neal (1992) Snow Crash, New York: Bantam.

Taylor, Paul A. (2001) 'Informational Intimacy and Futuristic Flu: Love and Confusion in the Matrix',

Information, Communication and Society 4(1, March): 74-94.

Thompson, E. P. (1967) 'Time, Work-Discipline, and Industrial Capitalism', Past and Present 38 (Dec.):

56-97.

Thrift, Nigel (1981) 'Owners' Time and Own Time: The Making of a Capitalist Time Consciousness, 13001880', Lund Studies in Geography, series B. 48: 56-84.

Thrift, Nigel (1996) Spatial Formations. London: Sage.

Virilio, Paul (1986) Speed and Politics. New York: Semiotext(e).

Virilio, Paul (1995) The Art of the Motor. Minneapolis: University of Minnesota Press.

Virilio, Paul (1997) Open Sky. New York: Verso.

Weiser, Mark and Seely Brown, John (1997) 'The Coming Age of Calm Technology', in Peter Denning and

Robert M. Metcalfe (eds) Beyond Calculation: The Next Fifty Years of Computing, pp.75-87. New York:

Copernicus.

Williams, Raymond (1979) Politics and Letters. London: NLB. 


\section{University Library}

\section{- M M I N E R VA A gateway to Melbourne's research publications}

Minerva Access is the Institutional Repository of The University of Melbourne

Author/s:

HASSAN, R

Title:

Network Time and the New Knowledge Epoch

Date:

2003

Citation:

HASSAN, R. (2003). Network Time and the New Knowledge Epoch. Time \& Society, 12 (2/3), pp.225-241. https://doi.org/10.1177/0961463X030122004.

Publication Status:

Published

Persistent Link:

http://hdl.handle.net/11343/34884 